\title{
The integration of renewable energy sources and electric vehicles into the power system of the Dubrovnik region
}

Anamarija Šare ${ }^{2 *}$, Goran Krajačić ${ }^{1}$, Tomislav Pukšec ${ }^{1}$ and Neven Duić ${ }^{1}$

\begin{abstract}
Background: In order to reduce greenhouse gas emissions, governments seek to replace conventional fuels by renewable ones. Nowadays, most attention is paid to electric vehicles in the transport systems and the use of renewable energy in the power systems. The aim of this work is to achieve a $100 \%$ renewable and sustainable system and to examine the impact of electrification in the transport sector on the power curve and the integration of renewable energy into the power systems of the Dubrovnik region up to 2050.

Methods: The analyses of different charging regulation models for the electric vehicles were derived in the EnergyPLAN, which is a computer model for Energy Systems Analysis of the major energy systems and runs on an hourly basis. Calculations were done for selected years-2020, 2030 and 2050. Charging models provided in the EnergyPLAN were dumb charge, flexible demand, smart charge and smart charge with vehicle-to-grid. For each year, two different charging models were selected. Charging regulations according to three tariff models, based on a lower and higher electricity price, with different distributions, were also done for 2050, i.e. tariff model 1, 2 and 3.

Results: The results for the year 2020 showed no difference between the models. In 2030, smart charge gained better results than a flexible demand. In 2050, the flexible demand allowed to achieve better results than the smart charge with vehicle-to-grid and the tariff model 1, while tariff model 3 provided the best results for 2050. It is also shown that the energy systems which include electric vehicles have a greater impact on the reduction of a critical excess electricity production than the systems excluding electric vehicles.

Conclusions: The power system of the Dubrovnik region was set up as an isolated system, and the electric vehicle batteries are the only storage provided. The results showed that each scenario yielded an excess in electricity produced in the system, which means that the available storage was insufficient and there was a need for more storage capacities in order to achieve a $100 \%$ renewable and sustainable power system.
\end{abstract}

Keywords: Electric vehicles; Vehicles-to-grid; Renewable energy sources; Electric distribution system; Smart charge

\section{Background}

Fuel consumption in the transport sector contributes significantly to the overall greenhouse gas emissions. The transport sector in the European Union participates with a share of $31.7 \%$ in the total final energy consumption [1] and with a share of $20 \%$ in the total greenhouse gas emissions [2]. Joining the European Union, Croatia has assumed the obligations of the Directive 2009/28/

\footnotetext{
* Correspondence: anamarija.sare@gmail.com

${ }^{2}$ Maritime Department, University of Dubrovnik, Dubrovnik, Croatia Full list of author information is available at the end of the article
}

EC, which among other things require that each member state by 2020 achieves a minimum share of renewable energy in the final energy consumption in transport by $10 \%$ [3]. Croatia has also published the 'Energy Strategy' following the example of the European Union (EU) which commits to achieve a $20 \%$ production from the renewable energy sources (RES) in the total energy production by 2020 [4]. Promoting the electrification in the transport sector as well as an electricity production based on RES would enable the achievement of these goals. Due to the intermitted electricity production of RES, the corresponding energy systems should include significant reserves in a 
form of conventional energy sources or significant capacities of energy storages. It leads to an increase in the prices of electricity and the overall energy system and limits a wider distribution of RES. The increased use of electric vehicles (EVs) provides a significant capacity of the distributed battery chargers, being connected to the grid, for creating new possibilities to integrate RES in the power systems. The study presented in [5] analysed the optimal investments and the scheduling of distributed energy resources with uncertainty in the electric vehicle driving schedules. The results of the study have shown that EVs can have a significant impact on a distributed energy resource investment, provided the payback periods are relatively small. On the other hand, RES are proven to reduce electricity prices in the short term as it is shown in the case study carried out for Germany [6]. These two technologies can benefit from each other because EVs can provide storages of a huge capacity for the electricity produced by intermitted RES, with a quick response in a time of peak demand, while RES have proven to be cost effective and a clean way of the EV energy supply [7]. EVs can represent the containers of the electricity that might be connected to the grid in order to supply the power system during the lack of electricity production from RES, what is also known as a Vehicle-toGrid (V2G) model [8].

Some previous studies have been performed which have considered the integration of RES into the power systems. Most of them indicated a need for future work and improvements. The analysis of the integration of RES into the power system of Macedonia [9] was carried out using the EnergyPLAN program. EnergyPLAN is a computer model for an Energy Systems Analysis of the major energy systems. The program runs on an hourly basis and is suitable for the analysis of energy systems of regions and countries. The results showed an increase in the RES electricity production by $13 \%$, a decrease in $\mathrm{CO}_{2}$ emissions as well as a decrease of critical excess of electricity production. Another case study of Macedonia was performed for a 50 and $100 \%$ share of RES in the power system [10]. It is concluded that a share of $50 \%$ is achievable by applying mandatory directives and reducing the electricity consumption. In both cases, a higher percentage of RES would be considered if it were combined with some kinds of electricity storage such as EVs. Higher implementation of RES into the power system of Serbia was also analysed using the EnergyPLAN [11]. These authors suggested a future analysis of the new tariff models for the electricity prices. The case study of the $100 \%$ renewable power system was done for Croatia [12], and the result points to the possibility of achieving a $78.4 \%$ share of RES in the electricity production as well as a reduction of $\mathrm{CO}_{2}$ emissions by $20 \mathrm{Mt}$. The authors of the study dealing with a $100 \%$ renewable energy system of Portugal [13] and another study analysing a higher penetration of wind energy into the power system [14] indicated the need of energy storages in order to achieve these goals. The importance of the role of storages in the power systems with high penetration of RES is emphasised in a doctoral thesis [15] in order to maintain the security of electricity supply and to have less negative impact on the environment. It was concluded that a $100 \%$ renewable system could be achieved if it is combined with energy storages and if it is not set up as an isolated system.

Most of the previous studies indicated the need for energy storage, and one of the possible options is the integration of EVs into the power systems. In a doctoral thesis [16], Denmark's power system, with a high penetration of wind energy, was analysed. Using the EnergyPLAN program, including the V2G model, it was concluded that the V2G model provided a better stability of the energy supply than the existing capacity of conventional power plants. The author suggested a future analysis of different charging models for EVs in order to achieve an optimal integration of EVs into the power system. Previous studies $[17,18]$ demonstrated that the distributed charging stations would provide a more stable and flexible power system, as well as a minor impact on peak loads.

The aim of this paper is to achieve a $100 \%$ renewable energy system with the use of EVs. The system should be regulated by way of optimum EV charging cycles in an order that the planned electricity production meets the needs of the demand in the best possible way. This paper was prepared as part of the i-RESEV project (Information and Communication Technologies (ICT) - aided integration of electric vehicles into the energy systems with a high share of renewable energy sources) which deals with the implementation of EVs into the power system with a high share of RES in the electricity production that is controlled by a widespread use of ICT tools [19]. The paper will not deal with communication technologies between the vehicles and the energy system, but will only use IT tools.

The analyses provided in this work are done for the Dubrovnik region which includes the city of Dubrovnik with its surroundings. It is situated in the southern part of Croatia at $42^{\circ} 38^{\prime} 25^{\prime \prime} \mathrm{N}$ and $18^{\circ} 06^{\prime} 30^{\prime \prime} \mathrm{E}$. Due to the significant potential of RES, such as solar radiation, hydro and wind energy, the computations should be carried out for a wider area of the Dubrovnik region. In order to achieve a $100 \%$ renewable system, analyses had to be carried out according to both the demand and supply side of the power system. The supply side is obtained from RES including hydro, solar and wind potential of the region. Basic hourly data of the electricity demand and RES potential were taken for the year 2010. The aim of this work is to predict the future capacity to meet the 
consumer needs, by using the known power consumption and the consumption calculations by 2050 , as well as the existing installed capacity of power generation. The regulation of the power system is planned to be carried out using EVs as the energy storage. The data on the EVs are based on the gathered information on the number of vehicles in the region and their driving cycles for the year 2010. Year 2010 represented the reference year based on which the future energy plan till 2050 was derived for the Dubrovnik region power system, with the selected scenarios for the years 2020, 2030 and 2050. The EnergyPLAN program is used to optimize all the components of the electric power system so that the production satisfies the demand. The EnergyPLAN analysis is carried out in hourly steps for 1 year, and the consequences are analysed on the basis of different optimisation strategies. The EnergyPLAN manual with the instructions for use is available online [20]. Analyses of some previous studies, abovementioned in the text, were carried out using the EnergyPLAN model.

Previous studies have demonstrated that the energy systems with a high penetration of RES in the electricity production need to contain some kinds of electricity storage to enable an optimal functioning of the system in a way that the planned electricity production meets the needs of the demand in the best possible way. The goal of this work is to achieve a $100 \%$ renewable energy system using the EVs as the electricity storage. The power system of the Dubrovnik region was set up as an isolated system, so that all of the electricity produced from RES had to be used at a time or stored in the EV batteries. Optimisation of the power system is carried out in the EnergyPLAN using the regulation of the system according to the different EV charging models. Beside the regulation by different EV charging models, analyses were carried out by setting different tariff models of the electricity prices in order to regulate EV charging during the lower tariff and low electricity demand. The results showed that the planned electricity storage is not large enough to store all of the electricity planned to be produced from RES, and the power system has to consider the critical excess in electricity production (CEEP). When we compare this work with some previous studies mentioned above, dealing with a similar problem and not realizing $100 \%$ renewable systems, some of them allowed to achieve systems with a high penetration of RES.

This work represents a good basis for future work in energy system planning related to the Dubrovnik region, as well as for other regions, cities and states that can be considered as an independent energy system. The results of the work showed that there is more work to be done with regard to the optimisation of the energy system in order to achieve sustainability of the system, to encourage the production from RES and reduce the negative impact on the environment and society. Some other kinds of storages need to be taken into consideration, and new analyses need to be performed using EV charging regulations strategies.

\section{Methods}

The Dubrovnik area is supplied from the electricity produced by the Dubrovnik hydroelectric power plant working within the Croatian power system with a capacity of $108 \mathrm{MW}$ and is owned by the Croatian Electrical Utility (HEP). It is not only supplying the Dubrovnik region, but also the surrounding areas. The Dubrovnik area has a considerable potential of renewable sources and plans to construct new facilities for hydropower, wind power and solar radiation, which has been taken into account in this paper when planning the production for future scenarios. Production from RES presents a challenge in the operation of the power system, as it is explained in the literature [21]. It depends on the weather conditions, which is the reason why often an excess or a shortage of production occurs. That is why it is necessary to provide reservoirs for the electricity produced and the batteries of EVs. The assumption is that batteries serve as a storage for the excess of electricity produced; while, on the other hand, they can also feedback energy to the grid during the lack of electricity production, the so-called vehicle-to-grid. It is necessary to know the number of EVs that will be entering the system by 2050 in order to calculate the capacity of battery storage. It is assumed that EVs are not always available for charging, so it is necessary to determine their availability for charging in order to provide the capacity of the transport electricity demand. Calculations of the capacity are done using driving cycles and the number of vehicles which are available at a certain time. The method used for the optimization of the electric power system was carried out in the EnergyPLAN by use of various models of EV charging. The impact of EV charging models on the electricity demand, as well as their impact on the CEEP production from RES was analysed.

The paper analyses the power system, which includes the production from RES to meet the consumption needs. The flow chart in Fig. 1 shows the methodical flow including electricity supply, demand and electricity storage of the energy system. The EneryPLAN input data were previously calculated using Excel and HOMER. HOMER is a computer program that enables technological and economical analyses of micro grid energy systems powered by RES. In this work, HOMER is used to calculate wind electricity production using the known hourly wind speed data, as it is explained later in the text. The EnergyPLAN input data consist of hourly distribution curves of all the components of the system and the data on their total year capacity. Analyses were carried out for three 


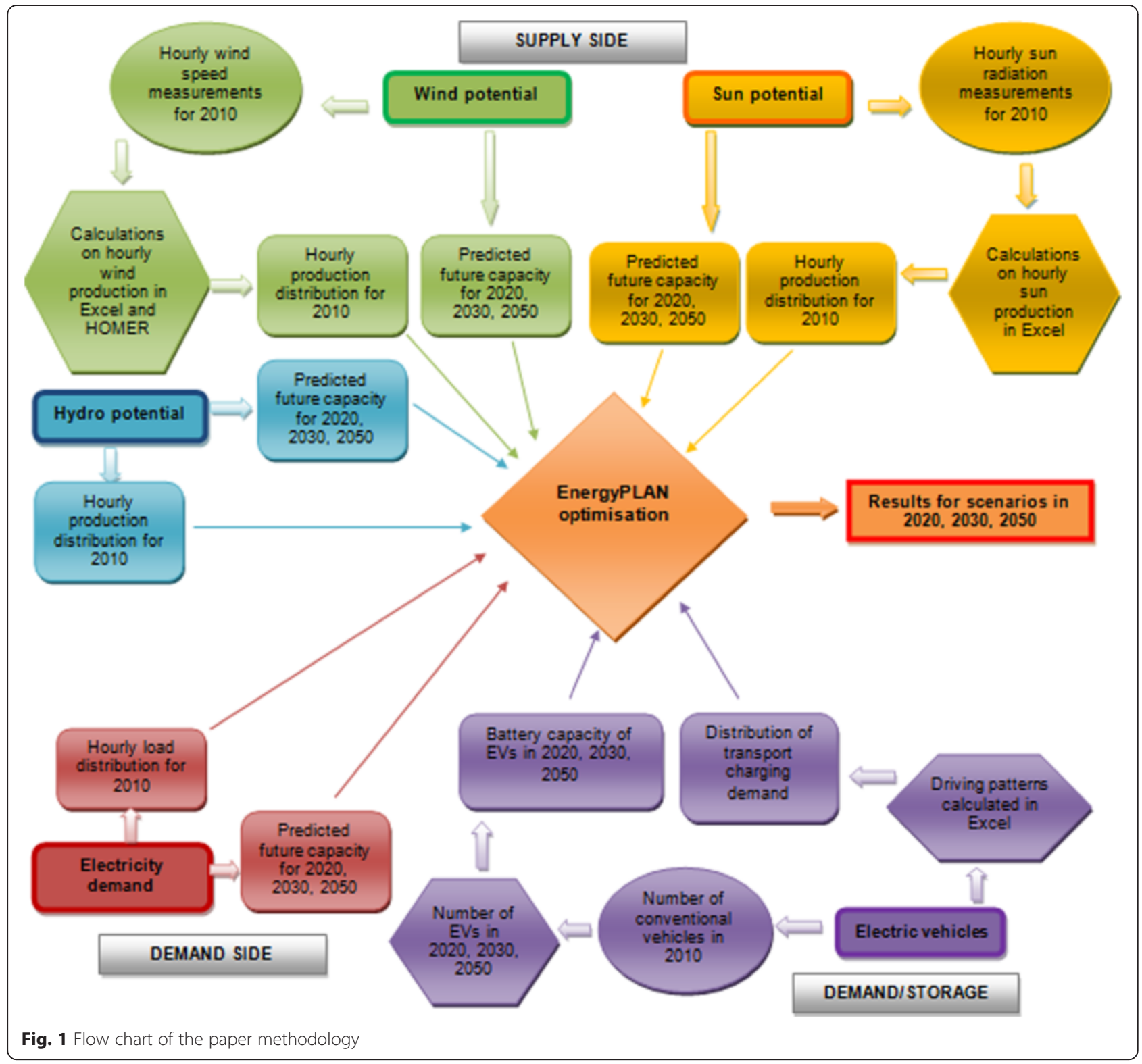

selected scenarios-year 2020, 2030 and 2050. The hourly distribution curves were the same for each scenario but the capacities were changed. The next step was the EnergyPLAN optimisation using different regulation models in order to provide the results for scenarios in 2020, 2030 and 2050.

\section{Input data for the EnergyPLAN calculations}

The input data for the EnergyPLAN calculations consist of the installed capacity data, the demand capacity data and their hourly distribution curves for a given year. The EnergyPLAN model is used to optimize the energy system of the Dubrovnik region by the given input data on electricity production and electricity demand for selected future scenarios for the years 2020, 2030 and 2050.

\section{Hydroelectric power plant production}

The hourly distribution curve of the electricity production of the Dubrovnik hydropower plant was obtained from the data taken for the year 2010. The data were purchased from the HEP Group (HEP d.d.-Hrvatska elektroprivreda d.d.), the Croatian national electricity company, for each hour of the year. The description of the power plant and its work is presented in [22]. The projected future capacities of hydropower plant production are shown for selected scenarios in Table 1. 
Table 1 Capacity of the production units for all scenarios

\begin{tabular}{llll}
\hline Year & 2020 & 2030 & 2050 \\
\hline Installed capacity of hydropower plant (MW) & 70 & 85 & 100 \\
Installed capacity of wind turbines (MW) & 32 & 160 & 320 \\
Installed capacity of photovoltaic systems (MW) & 9 & 18 & 36 \\
\hline
\end{tabular}

\section{Wind potential}

The hourly wind production distribution curve was derived from the measurement data of wind speeds taken from the Croatian Meteorological and Hydrological Service for the year 2010. The data were processed by using the HOMER program, which is the micro power optimization model which details were given in the literature [23]. In this work, HOMER is only used to process the data of wind speeds for a particular wind farm to obtain the production based on wind energy for the Dubrovnik region in the year 2010. The wind speed distribution for the year 2010 was analysed using HOMER as shown in Fig. 2 and the hourly wind production was provided for the installed wind capacity of $6 \mathrm{MW}$. The maximum wind speed for the year 2010 was $21.4 \mathrm{~m} / \mathrm{s}$. The curve of wind production per hour obtained by HOMER was used in further calculations where the higher installed capacities were distributed using the provided curve. Capacities of the future installed wind farms were projected up to 2050. It was carried out by a given projection of the Croatian Ministry of Economy [24]. The projected future capacities of wind power production for selected scenarios are shown in Table 1.

\section{Solar potential}

Dubrovnik region has $2623 \mathrm{~h}$ of sunshine per year, and it belongs to the areas with the highest irradiation on Croatian territory. Maximum solar irradiation for the year 2010 was $981 \mathrm{~W} / \mathrm{m}^{2}$. The hourly distribution curve of the solar production was derived from the measurement data of the solar radiation for the year 2010, which were taken from the Croatian Meteorological and Hydrological Service. The future installed capacity was projected up to 2050 by a given projection of the Croatian Ministry of Economy [24]. The projected future capacities of solar power production for selected scenarios are presented in Table 1.

\section{Electricity demand}

The hourly distribution curve of the electricity demand for the Dubrovnik region was obtained from the measurements of the substation Komolac. The data were provided for the year 2010 by the Croatian Electricity Company-distribution system operator, Elektrojug. The maximum power demand for 2010 reached 64.4 MW, with a total demand of $311 \mathrm{GWh} /$ year. The electricity demand by 2050 was modelled following a study available for Croatia [25]. The projected electricity demand for selected scenarios is shown in Table 5.

Figure 3 shows the relation in distribution between the load curve and the solar and wind potential of the Dubrovnik region in 2010 with the given maximum values of each month. There is a good relationship between solar radiation and energy demand during the summer period (in June, August and September), when both the load and radiation are high. During the winter period, there is a better relationship between demand and wind potential, as the wind potential is higher during October, November and December. The diagram illustrates a good correlation between solar and wind potential. During the summer period, the solar potential is high whereas the wind potential is low, while during the winter period, the opposite occurs. It can be expected that the most excess in electricity production from RES will be available in April, May and June when the load curve is low.

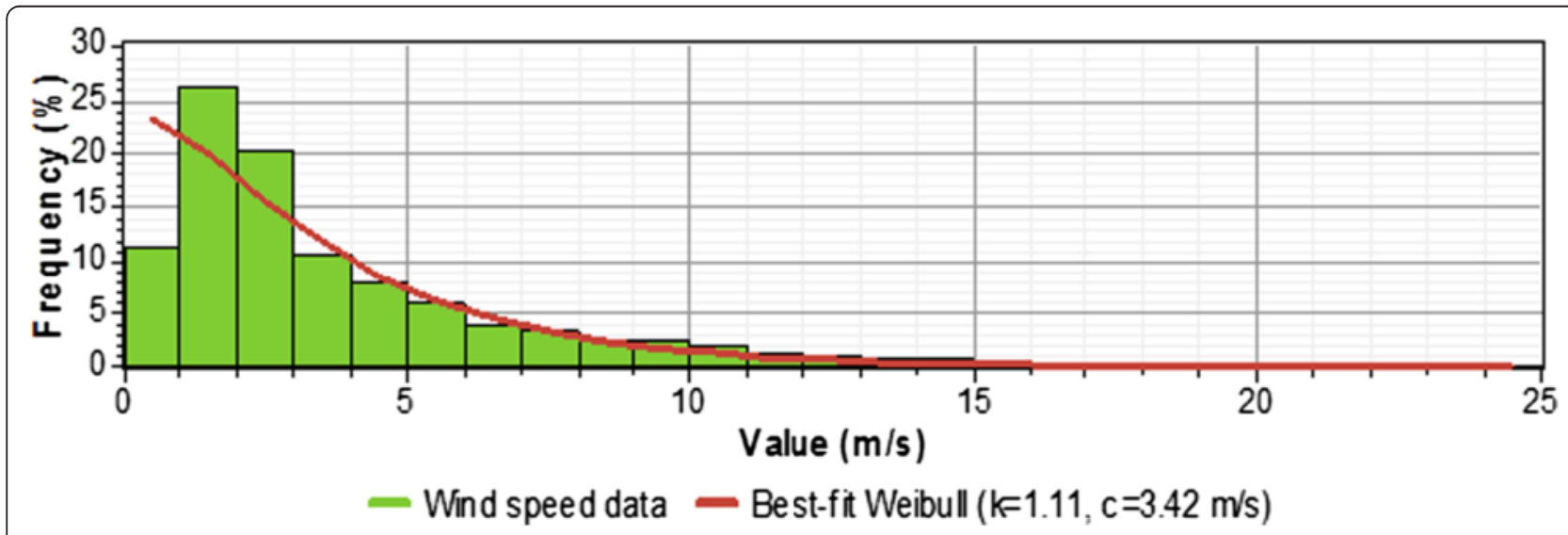

Fig. 2 Weibull distribution of wind speed for the year 2010. $k$ (shape parameter), c (scale parameter) 


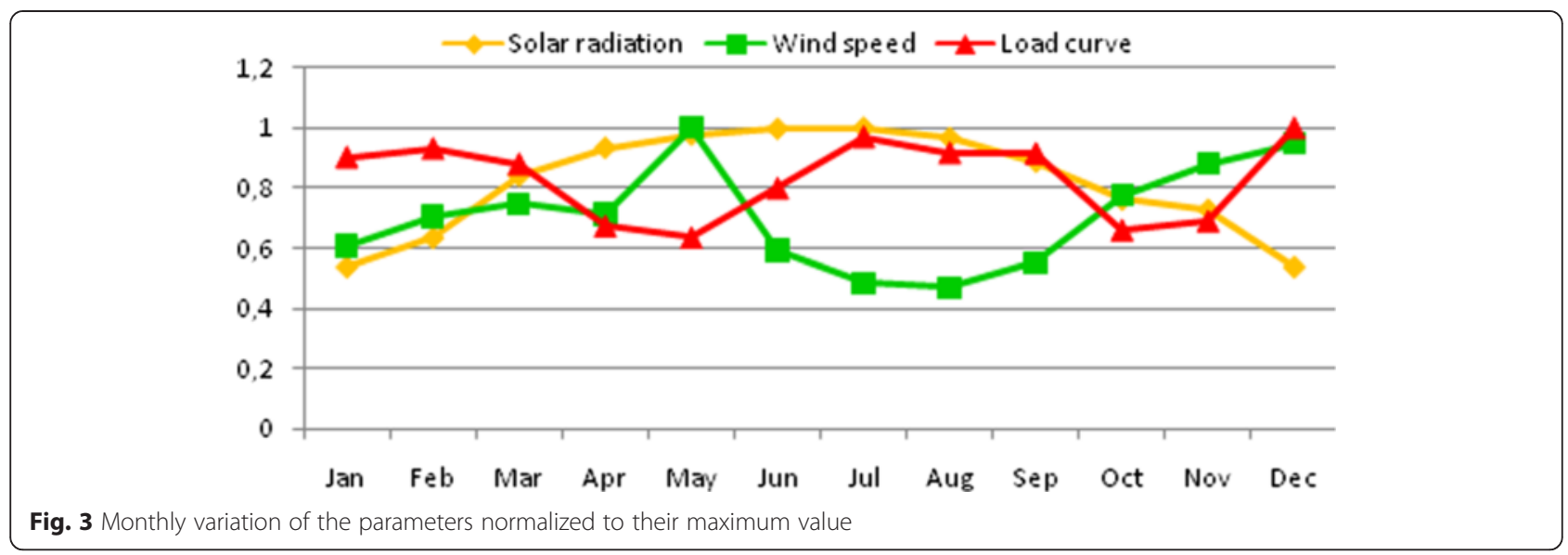

\section{Transport demand}

In order to obtain the transport demand, it was necessary to specify the penetration of electric vehicles by 2050 as well as the EV charging cycles. Many studies focusing on driving cycles and methods were performed for obtaining the transport demand [26-29]. EV penetration in the Dubrovnik region was obtained based on the number of personal vehicles on the territory of the Dubrovnik region in 2010 and a study done for Croatia, in which the EV penetration by 2050 was processed [25], as given in Table 2. It is assumed that in 2050, all of the vehicles will be replaced with EVs [25].

The capacity of the EV batteries is an important data for calculating the transport electricity demand. Some studies have analysed the battery sizes and their impact on the power system as well as their combination with different RES [30, 31]. In this work, this was not done in that way, as only three different battery sizes were chosen for EV fleet according to a test described in [32]. Following their battery size, the vehicles were divided into three groups by the provided number of EVs for all chosen scenarios, as shown in Table 3. Each group has the same number of vehicles and has its own kind of battery with different characteristics.

According to some studies [33, 34], the average daily trip of one particular vehicle is chosen to be $45 \mathrm{~km}$ for the entire Dubrovnik region. For the known capacity of each battery $\left(C_{\mathrm{B}}\right)$, its range and average daily trip, further calculations can provide the results on how long a full battery will last. The times of charging per day $\left(\mathrm{Ch}_{i}\right)$, for each battery type, are gained based on the battery life,

Table 2 Number of EVs in Croatia and Dubrovnik region for each scenario

\begin{tabular}{lllll}
\hline Year & 2010 & 2020 & 2030 & 2050 \\
\hline Number of EVs in Croatia & 0 & 10,723 & 581,802 & $1,368,462$ \\
Number of EVs in Dubrovnik & 0 & 146 & 7922 & 18,635 \\
\hline
\end{tabular}

which gives us the number of EVs $\left(E V_{t o t, i}\right)$, from each group, that need to be charged during one day, as shown in Table 4. The subscription $i$ represents each group of vehicles with small, medium and large batteries.

$$
\mathrm{Ch}_{i} \cdot \mathrm{EV}_{i}=\mathrm{EV}_{i, \text { tot }}
$$

With a known number of EVs that need to be charged per day, as well as their battery capacities per group, the whole daily capacity demand of the entire fleet $\left(C_{\mathrm{B}, \text { tot }}\right)$ can be calculated for all scenarios as shown in Table 5 .

$$
\begin{aligned}
& \mathrm{EV}_{\text {tot }, i} \cdot C_{\mathrm{B}, i}=C_{\mathrm{B}, i, \text { tot }} \\
& C_{\mathrm{B}, \text { tot }}=\sum C_{\mathrm{B}, i, \text { tot }}
\end{aligned}
$$

The total capacity data of the transport demand for each specific year has to be inserted in the EnergyPLAN, along with the hourly distribution curve for the same year, in order to be able to perform the calculations for the EnergyPLAN optimization. Due to the lack of transport data, it is considered that the capacity is going to be the same for each day of the year, so that one specific day is taken into account. The hourly distribution curve of the transport demand was modelled according to the traffic load profile for one specific day gained from the traffic study done for the Dubrovnik region [35] and illustrated in Fig. 4.

The inverted curve $\left(\mathrm{TLC}_{\mathrm{inv}}\right)$ is obtained from the known traffic load curve (TLC) for the Dubrovnik region which represents the vehicles that are available for

Table 3 Characteristics of selected types of EVs [32]

\begin{tabular}{llllc}
\hline Battery size & $\begin{array}{l}\text { Capacity } \\
(\mathrm{kWh})\end{array}$ & $\begin{array}{l}\text { Range } \\
(\mathrm{km})\end{array}$ & $\begin{array}{l}\text { Consumption } \\
(\mathrm{kWh} / 100 \mathrm{~km})\end{array}$ & $\begin{array}{c}\text { Power required } \\
\text { to the grid }(\mathrm{kW})\end{array}$ \\
\hline Small & 10 & 100 & 10 & 2.2 \\
Medium & 20 & 130 & 15.38 & 4.4 \\
Large & 35 & 180 & 19.44 & 7.8 \\
\hline
\end{tabular}


Table 4 Number of charging per day and number of each type of EVs to be charged

\begin{tabular}{lllll}
\hline & & \multicolumn{3}{l}{$\begin{array}{l}\text { Number of vehicles } \\
\text { to charge per day }\end{array}$} \\
\hline Size & Number of charging per day & 2020 & 2030 & 2050 \\
Small & 0.450 & 22 & 1188 & 2795 \\
Medium & 0.346 & 17 & 914 & 2150 \\
Large & 0.250 & 12 & 660 & 1553 \\
\hline
\end{tabular}

charging. The whole capacity for EV charging in one day $\left(C_{\mathrm{B}, \text { tot }}\right)$ is then distributed based on the inverted curve.

$$
\mathrm{TLC}_{\mathrm{inv}, j}=1-\mathrm{TLC}_{j}
$$

The sum of the data of the inverted curve is equal to 1 as the data will represent the percentage of the total battery capacity $\left(\mathrm{CLC}_{j}\right)$ needed in each hour of the day.

$$
\begin{aligned}
& \mathrm{CLC}_{j}=\frac{\mathrm{TLC}_{\mathrm{inv}, j}}{\sum_{j=1}^{24} \mathrm{TLC}_{\mathrm{inv}, j}} \\
& \sum_{j=1}^{24} \mathrm{CLC}_{j}=1
\end{aligned}
$$

The battery capacity per hour of the day is calculated by multiplying the percentage of the capacity load curve $\left(C_{j}\right)$ with the total battery capacity per each day $\left(C_{\mathrm{B}, \text { tot }}\right)$ :

$$
\mathrm{CLC}_{j} \cdot C_{\mathrm{B}, \text { tot }}=C_{\mathrm{B}, \text { tot }, j}
$$

Only one specific day is taken into account due to the lack of traffic data which is repeated throughout the year (Fig. 5).

\section{Calculations using the EnergyPLAN}

The calculations and the analysis of the energy system are performed using the EnergyPLAN, and the aim is that the production from RES satisfies the specified demand. The calculations allowed accounting of the values for each hour throughout the year, i.e. $8784 \mathrm{~h}$. The distribution curves of the hourly electricity demand and the production represent the input data for the EnergyPLAN program. The curves are the same for each scenario as it is assumed that the distributions of the production and the demand will remain the same throughout the whole year every year, whereas only the installed production

Table 5 Electricity and transport demand for each scenario

\begin{tabular}{lllll}
\hline Year & 2010 & 2020 & 2030 & 2050 \\
\hline Electricity demand (GWh/year) & 311 & 346 & 408 & 474 \\
Transport demand (GWh/year) & 0 & 0.4 & 21.86 & 51.43 \\
\hline
\end{tabular}

capacities from Table 1 and the annual demand capacities from Table 5 are changed according to each scenario. Production $\left(e_{\text {Total }}\right)$ represents the sum of all the renewable electricity production in the system:

$$
e_{\text {Total }}=e_{\text {Res }}=e_{\text {Res1 }}+e_{\text {Res2 }}+e_{\text {Res3 }}
$$

The total demand $\left(d_{\text {Total }}\right)$ is the sum of electricity demand $\left(d_{\mathrm{E}}\right)$ and transport demand which includes the flexible transport demand $\left(d_{\mathrm{FX}}\right)$, the smart and dumb charging regulation $\left(d_{\mathrm{BEV}}\right)$ and $\mathrm{V} 2 \mathrm{G}\left(d_{\mathrm{V} 2 \mathrm{G}}\right)$.

$$
d_{\text {Total }}=d_{\mathrm{E}}+d_{\mathrm{FX}}+d_{\mathrm{BEV}}+d_{\mathrm{V} 2 \mathrm{G}}
$$

The difference between the consumption and the production represents an excess or a deficit in the electricity production, depending on whether less or more energy is produced in a particular time span than it is needed.

$$
e_{\mathrm{pp}}=d_{\text {Total }}-e_{\text {Total }}
$$

In order to reduce an excess or a shortage of production, EVs have been added to the system. EVs are charged in times of an excess electricity production, and the V2G model is replacing the grid in times of shortage of production. When the system produces more energy than what is needed, the energy can be transmitted to the energy transmission lines, i.e. to the neighbouring energy markets. The CEEP represents the production of electricity used in export that goes beyond the capacity values of the energy transmission lines. In this work, the capacity values of the energy transmission lines were not set, so all of the excess of energy produced is observed as critical.

\section{EV charging models}

This paper considers four models of EV charging that are given by the EnergyPLAN:
(a) Dumb charge
(b) Flexible demand
(c) Smart charge
(d) Smart charge including V2G

Apart from these four models of EV charging, we analysed also the regulation of EV charging according to the different tariff models in electricity prices.

\section{Dumb charge}

The existing infrastructure of the power distribution sets certain limits on the integration of a large number of EVs into the power system. If the system does not include regulation, EV charging can influence the increase of a peak demand even in the case when the annual transport demand is low, for example, several thousand kilowatts [36]. The model of EV charging without any 


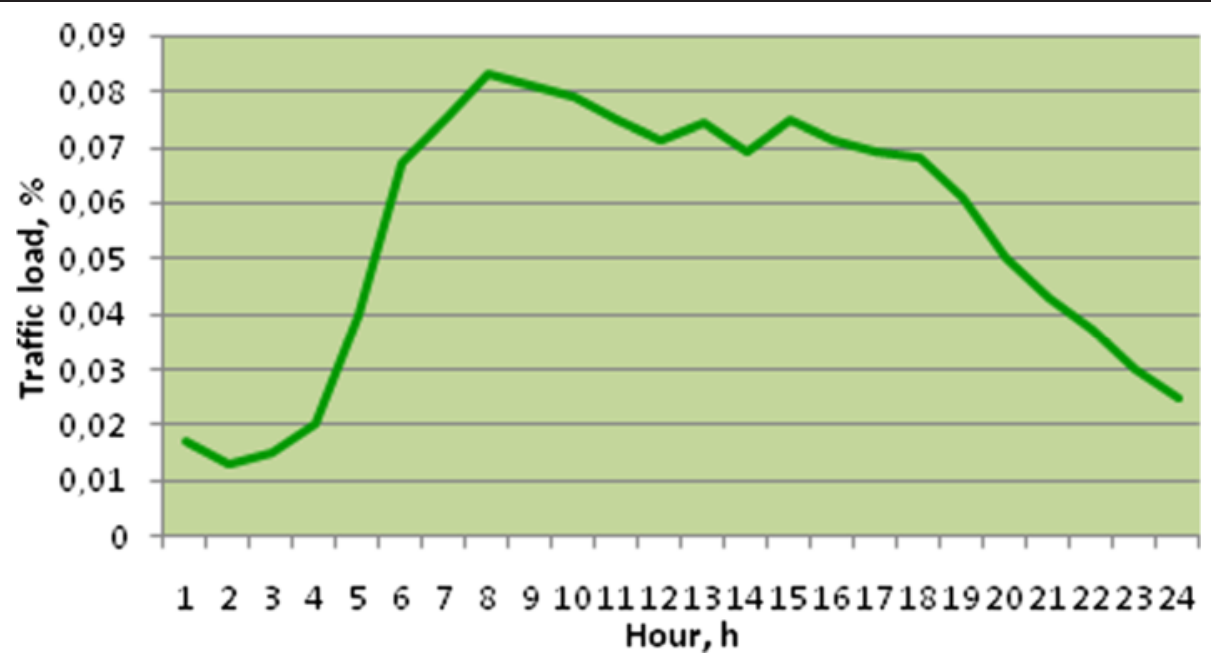

Fig. 4 Traffic load measured for the Dubrovnik region for one specific day

regulation in the system is called the dumb charge, and it is based solely on the needs and the habits of the drivers. Vehicles are loaded at the time when parked, depending on the demands of the consumers. A distribution curve of a dumb charge demand is gained by processing the transport demand data in Excel, as it was explained in the previous text focusing on the transport demand input data, and using an input distribution curve for the EnergyPLAN calculations. The dumb charge distribution represents the drivers' needs, as it can be assumed that all the vehicles parked are available for charging, since drivers do not use them at the time.

\section{Flexible demand}

Other additional technologies, including the controlled models of charging, have also been considered, for example the flexible electricity demand of transport demand. A flexible demand due to the charging EVs will ensure that the vehicles are full during a low electricity demand, mostly in the night hours. At the same time, it also regulates the EV charging during a high electricity production from RES, in order to reduce the production peak loads. The input distribution curve of the transport demand for the flexible demand model is the same as the one for the dumb charge. The difference is that the flexible demand regulation using the EnergyPLAN distributes the curve by changing its shape according to the charge of EVs, in order to charge the vehicles in the time of low electricity demand and during a large production from RES [37, 38]. A flexible demand cannot function without using ICT tools. The application of a flexible demand regulation requires the knowledge on weathercast

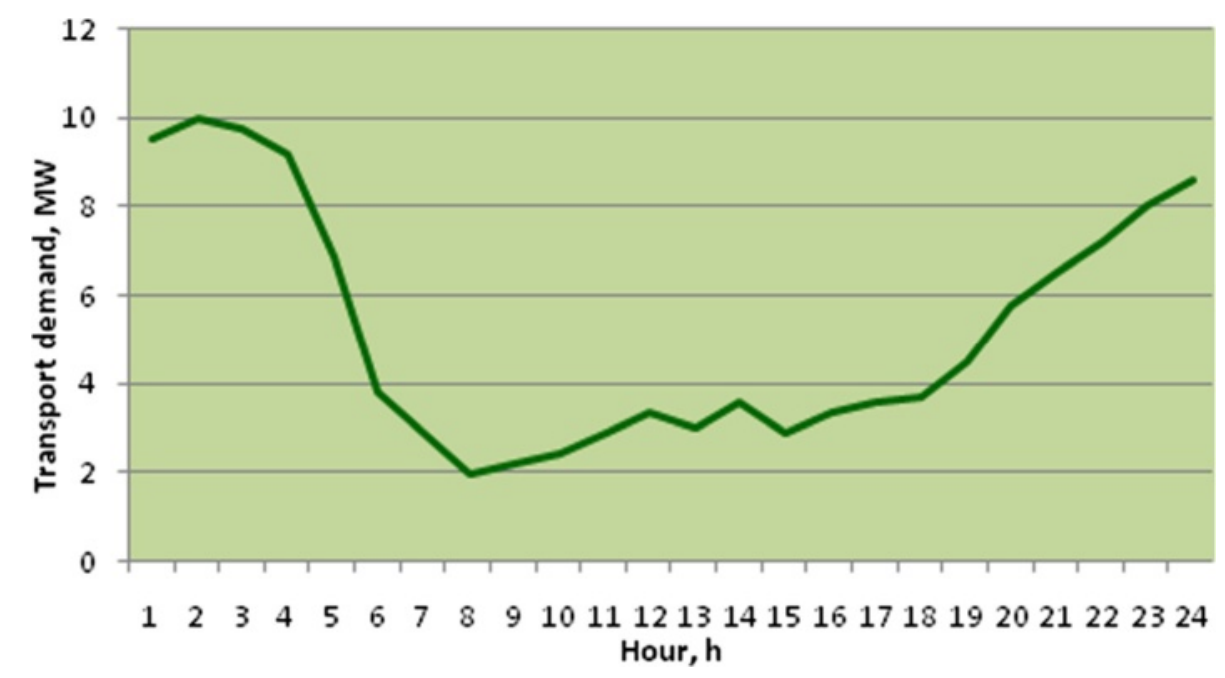

Fig. 5 Hourly distribution of electricity transport demand for one specific day in 2050 
in advance, in order to predict the production from RES and be able to estimate the needs for EV charging, so that the latter might not affect the electricity peak load demand and that they might reduce the peak load of electricity production.

\section{Smart charge}

Developing communication technologies between EV and the infrastructure of the power system might switch the EV charging during low electricity demand [39]. The smart charge model works in a way that it ensures that the battery of each vehicle is fully charged before switching off. Generally, the battery is full in the case of CEEP. However, when there is no CEEP, the model must ensure that the battery is charged before the driving cycle. Through smart charging, EVs can effectively contribute to the grid due to the rapid response to the needs of the energy system and the expected growth of the number of EVs in the future. The smart charge model provides the charging of EVs during low-power demand by controlling the charging of each vehicle in order to meet the needs of the drivers to recharge the vehicle at a certain time, as well as to control it for the purposes of the grid in order to provide a regulation and avoid an overloading of the grid [40]. The input curve for the smart charge regulation model in the EnergyPLAN is the distributed curve of transport demand for 2010 obtained in Excel based on the traffic data. It represents the transport electricity demand distribution based on the drivers' needs, and it is redistributed in the EnergyPLAN according to the smart charge regulation model.

\section{Smart charge using V2G}

$\mathrm{V} 2 \mathrm{G}$ is one of the many technologies in the energy sector that goes in favour of storing electricity. The vehicles use the power from the grid for driving and have also the ability to feedback electricity to the grid. They are partly controlled to meet the needs of the power system. The batteries of V2G vehicles are charged during a low demand and discharged during a shortage of a power generation in the system [41]. Analysis and testing for V2G were carried out using various models [42-44]. The smart charge model that includes V2G in the production system, allows charging V2G vehicles at the time of available CEEP and available battery capacity.

\section{Tariff models in electricity prices}

The regulation of EV charging is provided by setting three different tariff models for electricity prices in the EnergyPLAN. Each model is based on two tariffs, a lower tariff with a price of $0.45 \mathrm{kn} / \mathrm{kWh}$ and a higher tariff with $0.91 \mathrm{kn} / \mathrm{kWh}$ [45]. During day times, we have a higher tariff and during night times a lower one. The EVs are charged during the lower tariff period. Each tariff model has the same price for lower and higher tariffs but with a different distribution. In order to estimate the efficiency of the $\mathrm{V} 2 \mathrm{G}$ technology in the integration with the production of energy from RES, detailed simulations are carried out for each hour [46]. This type of analysis is made by using the EnergyPLAN for the $\mathrm{Du}$ brovnik region.

Different combinations of charging models were considered for each scenario, based on some future assumptions, as it is described in the results. Their impact on the system optimization was observed as we analysed the differences between the models according to their charging patterns, their impact on the maximum electricity demand and their correlation with the production from RES. The charging models and the formulae for all of the charging models are detailed, as described in the EnergyPLAN manual [20, 47].

\section{Results and discussion}

There have been some studies so far dealing with charging models for EVs. They compared regulated and unregulated charging and their effect on the electrical system [48-50]. Something similar is shown in this work. Considering the four existing models of the EV charging that have been explained in the previous text, some combinations of different charging models were selected for each of the scenarios by 2050 , according to their characteristics. Their analysis determined the impact of each model on the electricity demand and the impact on the production from RES. Comparisons were carried out for each scenario. The impact of EVs on the hourly electricity demand was analysed by using the increase of the maximum annual peak demand due to charges of EVs. The impact of the model on the electricity production from RES is investigated with regard to the increase in the CEEP, which indicates an excess of energy produced used in export. In the calculation, the values of the energy transmission capacity which might be provided to the neighbouring energy markets were not regarded. The system was set up as an isolated one.

\section{Scenario results for 2020}

Capacity input data of the consumption from Table 5 and the production of electricity from Table 1 for 2020 are entered into the EnergyPLAN, along with annual hourly distribution curves, as it was described in the previous text. The simulation in the EnergyPLAN is carried out on an hourly basis for the year 2020 and rested on two assumptions, scenario (A) and (B). Figure 6 presents the results for 1 week in January. Scenario (A) includes the model of a dumb charge and a flexible demand in the transport sector for year 2020. It is considered that in $2020,50 \%$ of the consumption will be flexibly regulated, while the other $50 \%$ of the vehicle 


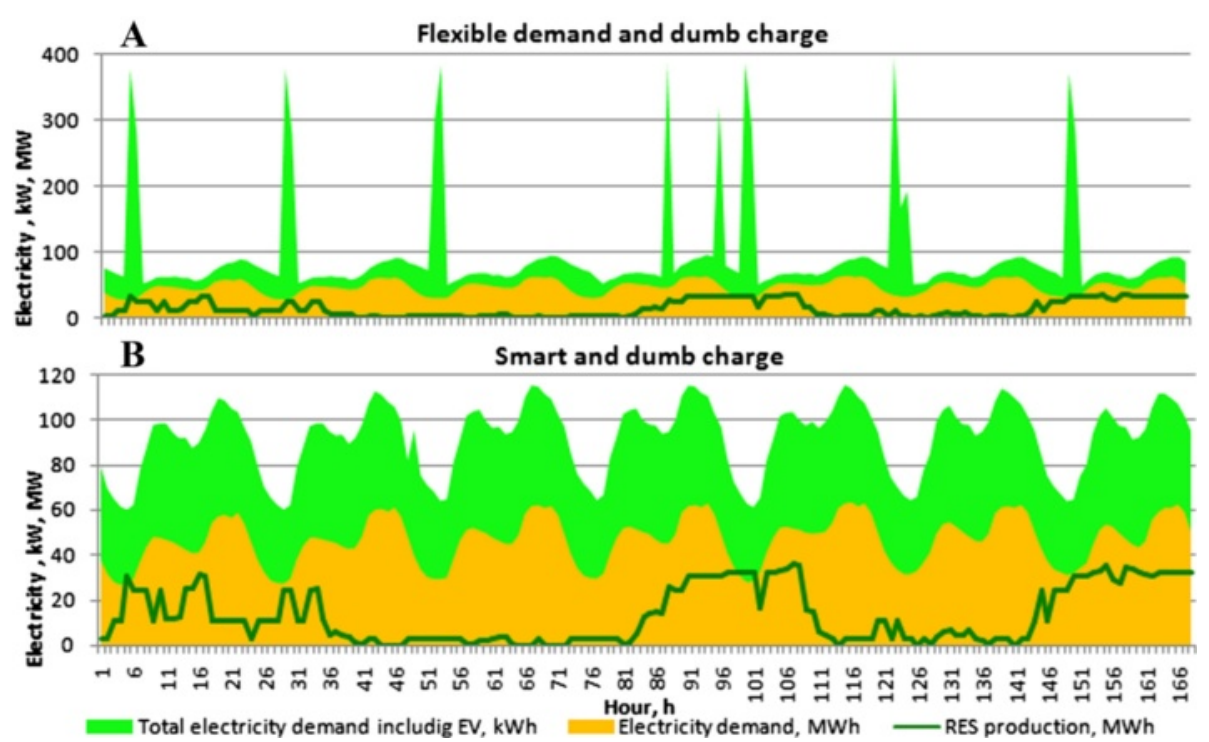

Fig. 6 Distribution of transport demand for two assumed EV charging models in 2020. The green field in the diagram represents the distribution of EV charging for scenario (A) and (B) in kWh as the capacity of the EV batteries is thousand times lower as compared to the electricity demand and RES production. There are only $146 \mathrm{EVs}$ in 2020 and the capacity of their batteries is too small

fleet will be charged by dumb charge since the regulation technology will not be fully represented in the transport sector in the near future. In scenario (B), the flexible demand is replaced with a smart charge, in the same way.

The results of two scenarios indicated a difference in the charging patterns due to the different regulation sets of EV charging models. The EV charging regulation in scenario (A), based on a flexible demand, provided some peeks in the transport demand distribution during the week. The reason for the peeks can be found in the fact that a flexible demand ensures to charge the EV batteries in the time of low electricity load and high production from RES, as it has been explained before in (b). Half of the EV fleet is charged according to the dumb charge which is based on the consumer needs, as has been explained before in (a). The hourly dumb charge curve is based on one specific day distributed through the whole year, which is the reason why the rest of the transport distribution is the same for each day of the week.

The charging regulation in scenario (B) provided a distribution with almost the same charging patterns for each day of the week. The reason is that half of the EV fleet is charged according to the dumb charge. Smart charge regulation did not provide any peeks as it controls EV charging in order to avoid overloads of the grid. Transport demand distribution is the same for each day because the regulation goes in favour of the drivers, which basically means that the smart charging regulation might partly ensure a distribution according to the dumb charge.
In order to compare scenarios (A) and (B), we analysed their impacts on the electricity load and CEEP, as shown in Table 6. The results showed no difference between the scenarios due to the small numbers of EVs in 2020, which points to a low capacity storage for the excess electricity produced. The increase in the maximum peak demand is the same in both scenarios as the EVs are partly charged according to the dumb charge. The number of the EVs projected for the year 2020 is not enough to store all of the electricity produced from RES as $33 \mathrm{MW}$ more storage capacity is needed to store all of the excess of electricity produced.

\section{Scenario results for 2030}

For 2030, it could be assumed that the EV charging regulation technology will be fully represented in the power system and is based on the fact that the two scenarios were determined and simulated in the EnergyPLAN. The results are illustrated in Fig. 7 for 1 week in January. For scenario (A), it is assumed that the whole EV fleet will be charged according to a flexible demand control, while for scenario (B), it is assumed that the EV

Table 6 Impact of assumed EV charging models on the electricity demand curve and the critical excess electricity production in 2020

\begin{tabular}{lcl}
\hline 2020 & $\begin{array}{l}\text { Increase in CEEP } \\
\text { (GWh/year) }\end{array}$ & $\begin{array}{l}\text { Increase of the maximum } \\
\text { peak demand }(\mathrm{kW})\end{array}$ \\
\hline Smart and dumb charge & 288.88 & 21 \\
$\begin{array}{l}\text { Flexible demand and } \\
\text { dumb charge }\end{array}$ & 288.88 & 21 \\
\hline
\end{tabular}




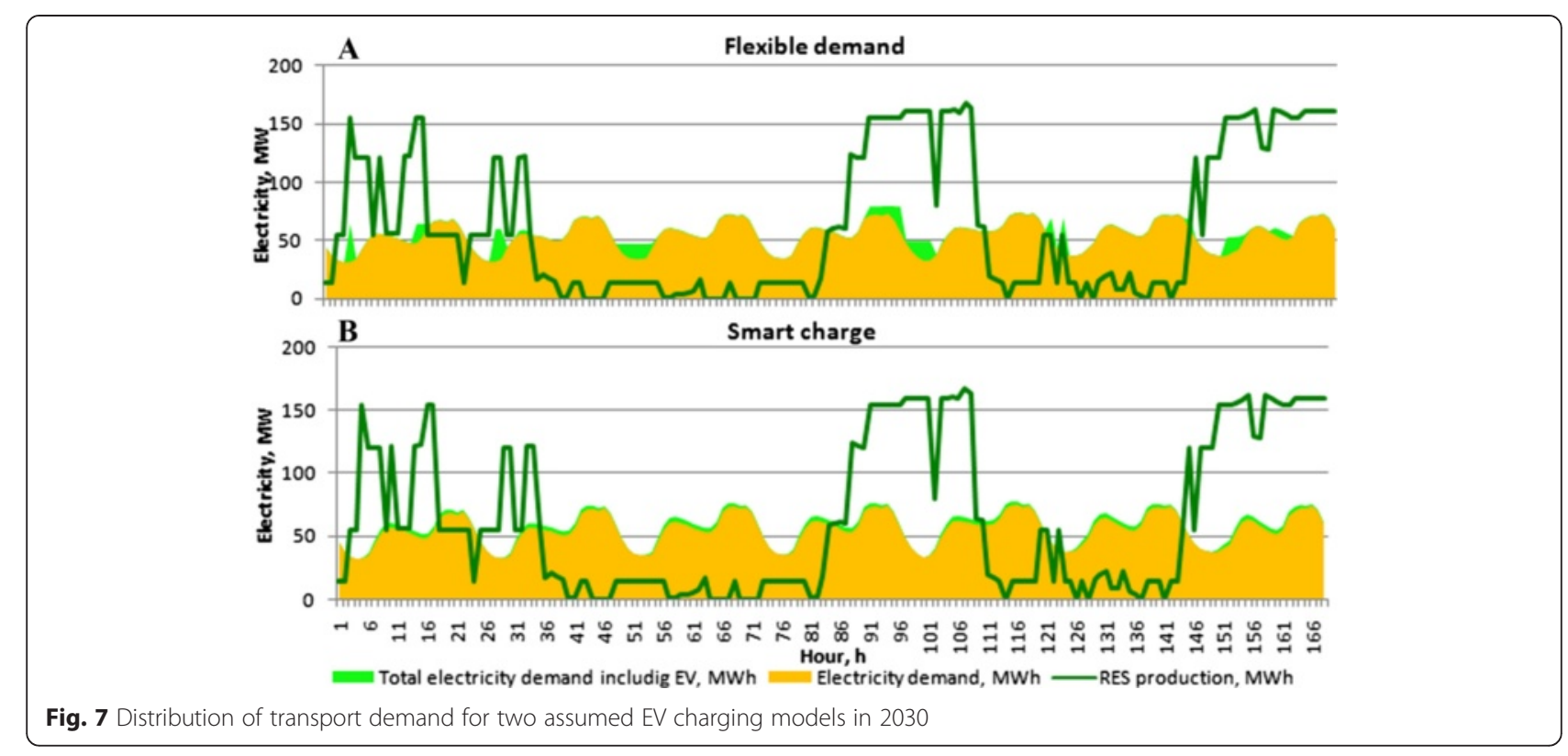

charging will be regulated by using a smart charge control.

The results in the diagram for scenario (A) demonstrated that the flexible demand regulation distributes the transport electricity demand in a way that the EVs are charged during low electricity demand and the time of high electricity produced from RES (b). The smart charge control in scenario (B) provided almost the same EV charging patterns for each day of the week. The reason is that the smart charge controls charging in a way that it meets the consumer needs, such as it was explained for scenario (B) for the year 2020 (c). When the results on impacts of electricity load and CEEP are compared as shown in Table 7, it might be concluded that smart charge control gives better results than the flexible demand control for 2030. There is no big difference between scenarios (A) and (B) in their impact on the increase in CEEP, although smart charge provides a storage with a slightly larger capacity of $47 \mathrm{~kW}$, and has a significantly lower impact on the increase of the maximum peak demand in the amount of 12.4 MW. This means that smart charge control distributes EV charging in order to provide more capacity storage for the excess electricity produced and avoids overloading of the grid. The capacity of EV batteries projected for 2030 was not

Table 7 Impact of the assumed EV charge models on the electricity demand curve and the critical excess electricity production in 2030

\begin{tabular}{lcl}
\hline 2030 & $\begin{array}{l}\text { Increase in CEEP } \\
\text { (GWh/year) }\end{array}$ & $\begin{array}{l}\text { Increase of the maximum } \\
\text { peak demand }(\mathrm{kW})\end{array}$ \\
\hline Smart charge & 646.45 & 9075 \\
Flexible demand & 646.86 & 21496 \\
\hline
\end{tabular}

large enough to store all of the excess of produced electricity forms of RES. To store all of the CEEP obtained in the system in 2030, $74 \mathrm{MW}$ more storage capacity is needed.

\section{Scenario results for 2050}

In the scenario for 2050, it is considered that a smart charge technology combined with V2G vehicles will be fully developed, and it is taken into account as a first assumption for EV charge control. V2G vehicles are able to feedback energy to the grid in the case of a lack of production from RES. According to the previous work [51], new models of charging regulation are analysed in this work, dealing with charging regulated by setting three different tariff models of the electricity prices. Tariff models are set for two different electricity prices, lower and higher tariff, with a different distribution shown in Table 8. Tariff model 1 is the one that is in use in the Dubrovnik region. Only certain sets of tariff for the final consumers were analysed in this work, and they are not formatted according to the prices on the wholesale market. The reason is that Croatia is not yet connected to any stock market, but in the future, it probably will be connected to the regional wholesale electricity market of Central Easter Europe along with Czech Republic, Hungary, Poland, Romania, Slovakia

Table 8 Tariff models in electricity prices

\begin{tabular}{lll}
\hline Tariff models & Lower tariff $(0,45 \mathrm{kn} / \mathrm{kWh})$ & Higher tariff $(0,91 \mathrm{kn} / \mathrm{kWh})$ \\
\hline Tariff model 1 & $9 \mathrm{pm}-7 \mathrm{am}$ & $7 \mathrm{am}-9 \mathrm{pm}$ \\
Tariff model 2 & $11 \mathrm{pm}-9 \mathrm{am}$ & $9 \mathrm{am}-11 \mathrm{pm}$ \\
Tariff model 3 & $2 \mathrm{pm}-6 \mathrm{pm} ; 12 \mathrm{pm}-6 \mathrm{am}$ & $6 \mathrm{am}-2 \mathrm{pm} ; 6 \mathrm{pm}-12 \mathrm{pm}$ \\
\hline
\end{tabular}


and Slovenia [52]. In scenario (A), it is assumed that the EV charging is regulated according to the flexible demand. For scenario (B), the regulation of EV charging is set up for a smart charge with both the V2G and the tariff model 1. Figure 8 illustrates the results for 1 week in January.

The results for scenario (A), presented in the diagram of Fig. 8, demonstrate that the flexible demand model for charging the regulation goes in favour of high electricity production and low electricity demand (b). The charging demand provides peeks in the time of high electricity production by RES, and in some parts of the week, it flattens the load curve by the regulation of EV charging during low electricity demand. Scenario (B) shows the same charging and discharging patterns of V2G vehicles according to the regulation sets for tariff model 1 . The vehicles are charged in a time of a higher tariff shown in Table 8 and discharged in a time of a lower tariff. The charging patterns are the same for each day of the week as the hourly curve of the transport demand, used as an input data for the EnergyPLAN, is distributed according to one specific day, as it was explained in the paragraph on the input data for the transport demand. The hourly curve of the transport demand represents the consumer needs where as the smart charge regulates the charging in order to satisfy those needs, which provide almost the same charging patterns for each day.
According to the results listed in Table 9, it can be concluded that scenario (A) allows to obtain better results in the case of CEEP because it provides an electricity storage of a larger capacity of up to $532 \mathrm{~kW}$. Scenario (B), however, gives better results according to the increase of the maximum peak demand. In comparison to the results for scenario (A), it decreases the maximum peak demand by $14 \mathrm{MW}$. In 2050, all of the conventional vehicles are replaced with EVs, but the installed capacity of RES in the system, projected for 2050 (see Table 1), still produces CEEP and needed a $125 \mathrm{MW}$ storage capacity to store all of the CEEP produced from RES.

Two more scenarios were analysed for 2050, according to the charging regulation controlled by different tariff models presented in Table 8, i.e. tariff model 2 and 3. It is assumed that a charging regulation will be provided by a smart charge and the V2G model as well as two different sets for tariff models. The plotted results are presented in Fig. 9 for both scenarios, whereas the results obtained for the impact of EV charging on both the increase in CEEP and the maximum peak demand are given in Table 10.

According to the results in Fig. 9, V2G are charged in a time of a lower tariff and discharged in a time of a higher tariff. The charging distribution is the same for each day of the week according to the regulation sets, as it was previously explained for scenario (B) for 2050.

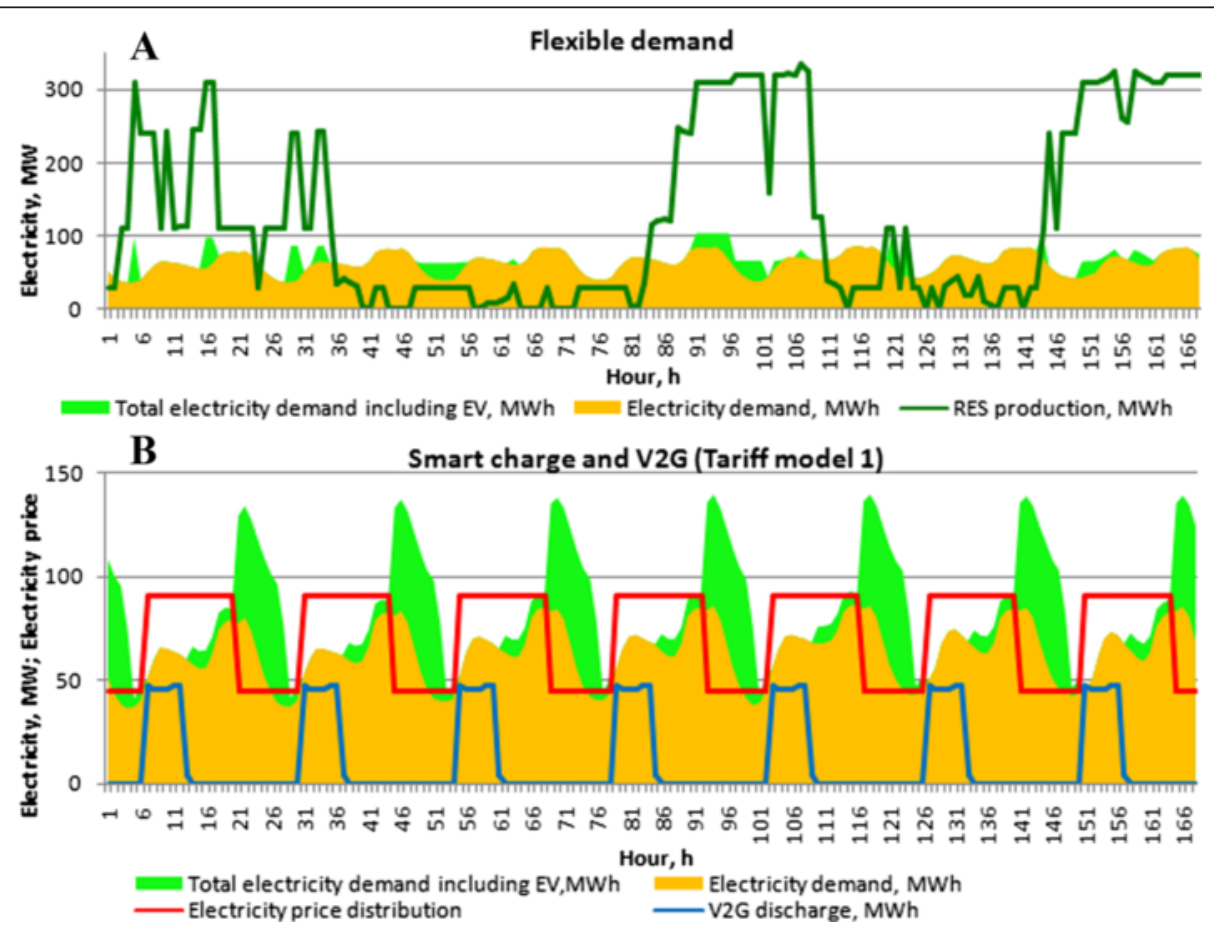

Fig. 8 Distribution of transport demand for two assumed EV charging models in 2050. The red line in the diagram (B) represents the electricity price distribution of the tariff model 1 explained in Table 8 
Table 9 Impact of assumed EV charge models on the electricity demand curve and the critical excess electricity production in 2050

\begin{tabular}{lcl}
\hline 2050 & $\begin{array}{l}\text { Increase in CEEP } \\
\text { (GWh/year) }\end{array}$ & $\begin{array}{l}\text { Increase of the maximum } \\
\text { peak demand (kW) }\end{array}$ \\
\hline $\begin{array}{l}\text { Smart charge and V2G } \\
\text { (Tariff model 1) }\end{array}$ & 1092.9 & 52,518 \\
Flexible demand & 1088.24 & 66,468 \\
\hline
\end{tabular}

The results presented in Table 10 illustrate a comparison between three different tariff models. It is shown that the regulation sets of tariff model 3 give best results compared to the other tariff models. Tariff model 3 provides a 1.3 MW larger storage capacity and has an $11 \mathrm{MW}$ less increase in the maximum peak demand compared to tariff model 1. Compared to tariff model 2, it provides a $1 \mathrm{MW}$ larger storage capacity and a 7.5 MW less increase in the maximum peak demand.

\section{The impact of EVs and RES penetration on CEEP}

In the EnergyPLAN, an additional analysis of the impact of EV penetration on the critical excess of annual electricity production is carried out for each scenario, which has resulted from an increase in installed capacity of renewable energy. Smart charge models for the analysis were selected from all scenarios.

The diagrams in Fig. 10 represent the relationship between the CEEP and the installed capacity of wind turbines (A) and photovoltaic systems (B), based on the assumption that EVs participate in the system and for the case that they do not participate in the system, for each scenario. From the diagram, it can be concluded that the CEEP is higher in the system without EVs, and the difference is most apparent in 2050. The reason is the larger number of EVs that represent higher storage capacity for the produced electricity. In 2020, there is a small number of EVs, of 146, so they have low storage capacity, which gives no big difference for the system if it includes EVs or not. That is why the lines for 2020 with and without EVs are overlapping. It can be seen from the diagram that in the case (A) CEEP is rising more rapidly with an increase of installed capacity for wind production in the power system than in the case (B). In the case (B), the CEEP is high, but does not increase much with an increase in the installed capacity of the photovoltaic systems, as it is true for the case (A), because its installed capacity is lower. However, a significant increase in CEEP from one scenario to another is noted. We would now draw our attention to a case where with the penetration of wind turbines, the implementation of EVs in the energy system reduces the CEEP, which reflects the expected situation in 2050 because of a larger storage capacity provided by a higher number of EV batteries. The EV storage capacities for 2020, 2030 and 2050 are listed in Table 5.

\section{Conclusions}

In this paper, three scenarios for the years 2020, 2030 and 2050 are presented, and an analysis was carried out

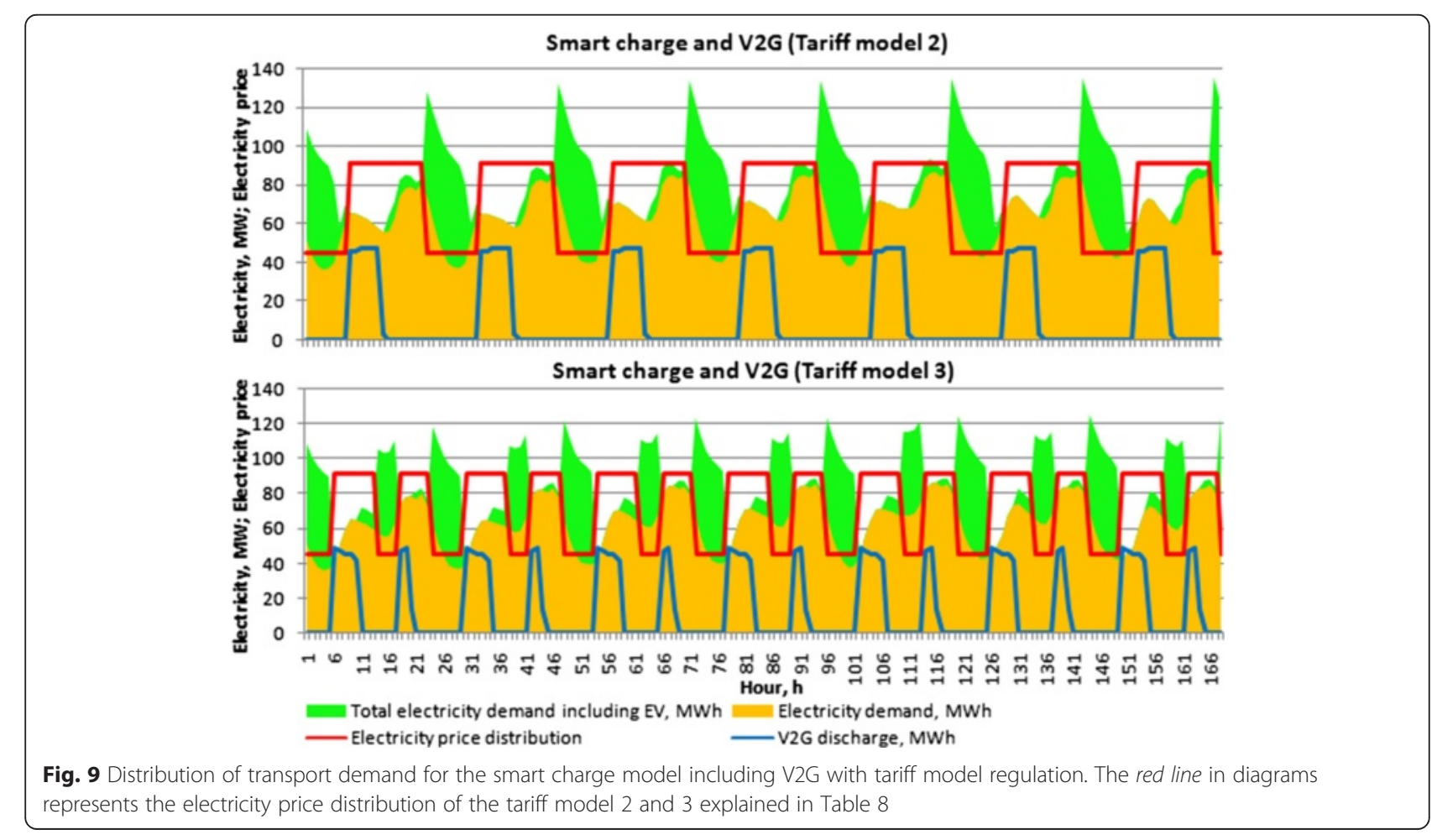


Table 10 Impact of tariff model regulation of EV charging on the electricity demand curve and the critical excess electricity production in 2050

\begin{tabular}{lcl}
\hline 2050 & $\begin{array}{l}\text { Increase in CEEP } \\
\text { (GWh/year) }\end{array}$ & $\begin{array}{l}\text { Increase of the maximum } \\
\text { peak demand }(\mathrm{kW})\end{array}$ \\
\hline Tariff model 1 & 1092.9 & 52,518 \\
Tariff model 2 & 1090.29 & 49,151 \\
Tariff model 3 & 1081.62 & 41,620 \\
\hline
\end{tabular}

to determine the influence of the EVs on both the hourly distribution demand curve and the production of energy from RES.

In 2020, both models have the same effect on the increase in the peak demand, reaching an amount of $21 \mathrm{~kW}$, as each model represented the same percentage of dumb charge. Both models generate CEEP in an amount of $288.88 \mathrm{GWh} /$ year. The charging demand distributions for the two assumed scenarios for the year 2020 are different, but their impact on both the maximum peak demand and the CEEP is the same due to the low number of EVs present in the system. The capacity of EV batteries is not large enough, and $33 \mathrm{MW}$ more storage capacity is needed in order to store the excess of electricity produced by RES.

Smart charge control is generally considered more favourable than flexible demand as it satisfies the needs of the drivers and avoids overloading of the grid. Flexible demand regulation, on the other hand, is aiming to reduce peak production and to recharge the vehicles at the time of low demand, but regulation is not implemented in order to satisfy the needs of drivers. In the scenario for 2030, a flexible demand regulation increases the CEEP by $0.41 \mathrm{GWh} /$ year and the peak demand is $12.4 \mathrm{MW}$ larger than in the case of smart charge. Smart charge provides better results, but there is still a need for a $74 \mathrm{MW}$ larger storage in the system for 2030.

The model of smart charge with both the V2G and tariff model 1 charging regulation, for the year 2050, is compared with a model of a flexible demand. A flexible demand control gave better results in reducing the CEEP in an amount of $4.66 \mathrm{GWh} /$ year less than for the V2G
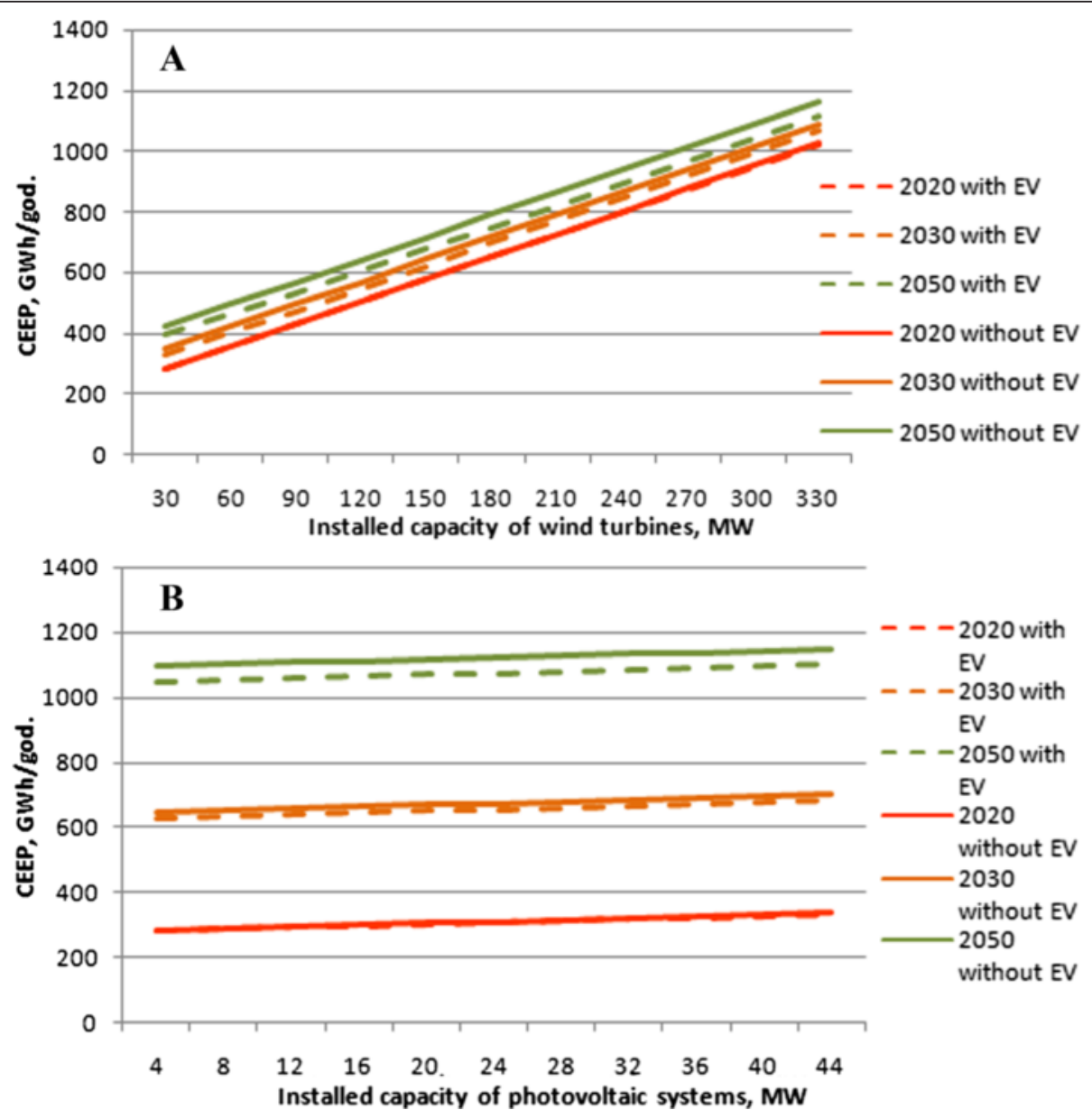

Fig. 10 Increase of the critical excess electricity production with penetration of RES in the energy system, the comparison of scenarios with the EVs in the system and without them 
model, but increased the peak demand by $14 \mathrm{MW}$ more than that of the V2G model. The reason is that in the model, which includes smart charge together with V2G vehicles, an additional regulation was introduced in order to meet the minimum cost, whereas the model, apart from the requirements of the driver and the grid, adjusts the electricity price in order to achieve a minimum charge cost. Vehicles are charged in a time of lower tariff and discharged in a time of higher tariff. There is still a need for $125 \mathrm{MW}$ of storage capacities in order to store all of the CEEP produced in the system.

Two additional scenarios were analysed for 2050 according to the different sets for the tariff models 2 and 3 . Tariff model 3 gave the best results according to the impact on the CEEP and the maximum peak demand, as compared to other scenarios presented for 2050. This leads to the conclusion that the optimal sets of tariff models could provide a better functioning of the power system in order to reduce the costs and to satisfy the needs of the system in the best possible way. Higher tariffs could be set up in a time of high electricity load and low production from RES and in the reverse case, we can do the opposite and set tariff to a lower price. The system could have more than two tariffs. Charging regulation according to the tariff models is something that could be part of the future work in system optimization. In order to improve an optimization of the electricity market, we need to consider an application of ICT tools which would provide the communication between consumer and supplier.

All of the scenarios have been set up as isolated systems in the EnergyPLAN optimization, and therefore, the CEEP and also a lack of production is appearing because the transmission line capacities for import and export are not specified. The paper also provides an overview of the CEEP increase accompanied by an increase in the installed capacity of RES. From this, it will be evident that the power system, which includes the EVs in the regulation of the relationship between production and consumption of electricity, produces less CEEP than the power system that does not include the EVs in the system. The EVs store the excess of electricity produced from RES and provide less CEEP in the system. This leads to the conclusion that a power system that includes RES cannot function without the electricity storage. Although EVs are present in the Dubrovnik region power system up to 2050, it appears that the EV battery capacities are not enough to store all of the electricity produced from RES. Some future work should consider more installed capacity of new storages for the region or maybe set up capacities of transmission lines for import and export of electricity in order to provide good functioning of the power system.

Although this work did not provide an optimal regulation of the power system by the chosen scenarios to achieve a $100 \%$ renewable electricity production, it derived guidelines in which direction future work should go and provided results that could be useful for further work. Due to the lack of data, the transport demand had to be distributed according to one specific day, and thus, some new information and new data should be considered in future investigations in order to provide more realistic results. This work can be helpful for the optimization of both the power systems in regard to the power produced by RES and the EV charging technologies developed for cities, regions or entire countries. In order to provide sustainability of such systems, they should contain enough storage capacities. There is more work necessary to be carried out to reach the sustainability of these systems and to apply alternative technologies with a more positive impact on the environment.

\section{Competing interests}

The authors declare that they have no competing interests.

\section{Authors' contributions}

The article was jointly prepared by all authors. All authors read and approved the final manuscript.

\section{Acknowledgements}

A financial support from the Croatian Science Foundation through the "ICT-aided integration of Electric Vehicles into the Energy Systems with a high share of Renewable Energy Sources" project is gratefully acknowledged.

\section{Author details}

${ }^{1}$ Faculty of Mechanical Engineering and Naval Architecture, University of Zagreb, Zagreb, Croatia. ${ }^{2}$ Maritime Department, University of Dubrovnik, Dubrovnik, Croatia.

Received: 4 February 2015 Accepted: 11 August 2015

Published online: 04 September 2015

\section{References}

1. European Commission (2010) Eurostat., http://epp.eurostat.ec.europa.eu/ statistics_explained/index.php/Consumption_of_energy. Accessed 23 Apr 2015.

2. EEA (2009) European Environment Agency., http://www.eea.europa.eu/. Accessed 23 Apr 2015.

3. Direktiva 2009/30/EZ Europskog parlamenta i vijeća, (2009). http://eurlex.europa.eu/legal-content/HR/TXT/PDF/?uri=CELEX:32009L0030\&from=HR. Accessed 23 Apr 2015.

4. "Strategija energetskog razvoja Republike Hrvatske" (2009) »Narodne novine«, br. 68/01., 177/04., 76/07. i 152/08. http://narodne-novine.nn.hr/ clanci/sluzbeni/2009_10_130_3192.html. Accessed 23 Apr 2015.

5. Cardoso G, Stadler M, Bozchalui MC, Sharma R, Marnay C, Barbosa-Póvoa A Ferrão P (2014) Optimal investment and scheduling of distributed energy resources with uncertainty in electric vehicle driving schedules. Energy 64:17-30.

6. Sensfus F, Ragwitz M, Genoese M (2008) The merit-order effect: a detailed analysis of the price effect of renewable electricity generation on spot market prices in Germany. Energy Policy 36(8):3086-3094. doi:10.1016/ j.enpol.2008.03.035.

7. Kempton W, Tomic J (2005) Vehicle to grid fundamentals: calculating capacity and net revenue. J Power Sources 144:268-279. doi:10.1016/ j.jpowsour.2004.12.025.

8. Kempton W, Tomić J (2005) Vehicle-to-grid power implementation: from stabilizing the grid to supporting large-scale renewable energy. J Power Sources 144:280-294

9. Ćosić B, Markovska N, Taseska V, Krajačić G, Duić N (2013) Increasing the renewable energy sources absorption capacity of the Macedonian energy system. J Renewable Sustainable Energy 5:4, 041805-1-041805-8 
10. Ćosić B, Krajačić G, Duić N (2012) A $100 \%$ renewable energy system in the year 2050: the case of Macedonia. Energy (Oxford) 48:80-87.

11. Batas Bjelić I, Rajaković N, Ćosić B, Duić N (2013) Increasing wind power penetration into the existing Serbian energy system. Energy 57:30-37.

12. Krajačić G, Duić N, Zmijarević Z, Mathiesen B, Anić Vučinić A, Carvalho M (2011) Planning for a $100 \%$ independent energy system based on smart energy storage for integration of renewables and $\mathrm{CO} 2$ emissions reduction. Appl Therm Eng 31:2073-2083.

13. Krajačić G, Duić N, Carvalho M (2011) How to achieve a $100 \%$ RES electricity supply for Portugal? Appl Energy 88(2):508-517.

14. Segurado R, Krajačić G, Duić N, Alves LM (2011) Increasing the penetration of renewable energy resources in S. Vicente, Cape Verde. Appl Energy 88(2):466-472.

15. Krajačić $\mathrm{G}$ (2012) The role of energy storage in planning of $100 \%$ renewable energy systems. University of Zagreb, Dissertation.

16. Pillai R, Jayakrishnan (2010) Electric vehicle based battery storages for large scale wind power integration in Denmark. Aalborg University.

17. de Gennaro M, Paffumi E, Martini G (2015) Customer-driven design of the recharge infrastructure and vehicle-to-grid in urban areas: a large-scale application for electric vehicles deployment. Energy 82:294-311.

18. Neaimeh M, Wardle R, Jenkins AM, Yi J, Hill G, Lyons PF, Hübner Y, Blythe PT, Taylor PC (2015). A probabilistic approach to combining smart meter and electric vehicle charging data to investigate distribution network impacts. In: Applied Energy. Elsevier (in press).

19. i-RESEV project (2012) ICT-aided integration of electric vehicles into the energy systems with a high share o renewable energy sources., http:// powerlab.fsb.hr/iresev/. Accessed 23 Apr 2015.

20. Lund H (2012) EnergyPLAN_advanced energy systems analysis computer model, documentation version 10.0., http://energy.plan.aau.dk/EnergyPLANVersion10-August2012.pdf. Accessed 23 Apr 2015.

21. Johansson B (2013) Security aspects of future renewable energy systems-a short overview. Energy 61:598-605.

22. Hidroelektrana Dubrovnik (2012) HEP Proizvodnja d.o.o., http://www.hep.hr/ proizvodnja/en/basicdata/hydro/dubrovnik/default.aspx. Accessed 23 Apr 2015.

23. National renewable energy laboratory (2005) getting started guide for HOMER version 2.1. USA. http://www.homerenergy.com/pdf/HOMER GettingStarted210.pdf. Accessed 23 Apr 2015.

24. Ministarstvo gospodarstva Republike Hrvatske (2012) http://oie-aplikacije mingo.hr/pregledi/Popuplzvjestaj.aspx?Reportld=5b47346e-67aa-4df2-9603fa83c47061e3\#P32ed9c04a3d843c08f17e75a12c7aad8_2_179iT1R0x0. Accessed 23 Apr 2015.

25. Pukšec T, Krajačić G, Lulić Z, Van Mathiesen B, Duić N (2013) Forecasting long-term energy demand of Croatian transport sector. Energy 57:169-176.

26. Metz M, Doetsch C (2012) Electric vehicles as flexible loads-a simulation approach using empirical mobility data. Energy 48:369-374.

27. Shah N, Cho B, Geth F, Clement K, Tant P, Driesen J (2011) Electric vehicle impact assessment study based on data-logged vehicle and driver behavior. Vehicle Power and Propulsion Conference (VPPC). IEEE. 1-6. doi:10.1109/ VPPC.2011.6043146.

28. He Y, Vankatesh B, Guan L (2012) Optimal scheduling for charging and discharging of electric vehicles. IEEE, TRANSACTIONS ON SMART GRID.3:095 - 1105. doi: 10.1109/TSG.2011.2173507.

29. Grahn P, Alvehag K, Söder L (2012) Plug-in-vehicle mobility and charging flexibility Markov model based on driving behavior. 9th International Conference on the European Energy Market (EEM). IEEE. 1-8. doi:10.1109/ EEM.2012.6254711.

30. Juul N (2012) Battery prices and capacity sensitivity: electric drive vehicles. Energy 47:403-410.

31. Fernández IJ, Calvillo CF, Sánchez-Miralles A, Boal J (2013) Capacity fade and aging models for electric batteries and optimal charging strategy for electric vehicles. Energy 60:35-43.

32. Perujo A, Ciuffo B (2010) The introduction of electric vehicles in the private fleet: potential impact on the electric supply system and on the environment. A case study for the Province of Milan, Italy. Energy Policy 38:4549-4561.

33. Kang DJ, Park S (2011) A case study on the grid impact of PHEV to distribution power system. Yonsei University. 44th Hawaii International Conference on System Sciences (HICSS), Kauai, HI, 4-7 Jan. 2011.IEEE. 1-6. doi:10.1109/HICSS.2011.2.
34. Clement K, Van Reusel K, Driesen K (2007) The consumption of electrical energy of plug-in hybrid electric vehicles in Belgium. Proceedings of the European Ele-Drive Conference. Brussels, Belgium, In.

35. Bando M, Bukvić I, Cvjetković I, Miličić N, Peran V, Vuković Z, Kosmat L, Landek S, Majstorović I, Njegovec M, Pološki D, Rigo A, Stepan Ž (2012) Prometna studija Grada Dubrovnika.

36. Lassila J, Kaipia T, Haakana J, Partanen J, Järventausta P, Rautiainen A (2009) Electric cars - challenge or opportunity for the electricity distribution infrastructure? European conference on smart grids and mobility, 53851 Lappeenranta, Finland.

37. Lund H, Münster E (2006) Integrated transportation and energy sector CO2 emission control strategies. Transp Policy 13(5):426-433.

38. Mathiesen BV, Lund H, Nørgaard P (2008) Integrated transport and renewable energy systems. Util Policy 16(2):107-116.

39. Markel T, Kuss M, Denholm P (2009) Communication and control of electric vehicles supporting renewables. Vehicle Power and Propulsion Conference (VPPC). IEEE 27-34. doi:10.1109/NPPC.2009.5289874

40. Bracale, A., Caramia, P., Proto, D. (2011) Optimal operation of smart grids including distributed generation units and plug in vehicles. International Conference on Renewable Energies and Power Quality (ICREPQ'11), Las Palmas de Gran Canaria (Spain), 13th to 15th April, 2011.

41. Brooks A, Lu E, Reicher D, Spirakis C, Weihl B (2010) Demand dispatch: using real-time control of demand to help balance generation and load. IEEE Power \& Energy Magazine., pp 20-29.

42. Kempton W, Kubo T (2000) Electric-drive vehicles for peak power in Japan. Energy Policy 28(1):9-18.

43. Kempton W, Letendre SE (1997) Electric vehicles as a new power source for electric utilities. Transp Res Part D: Transp Environ 2(3):157-175.

44. Miloš P (2011) Stochastic optimal charging of electric-drive vehicles with renewable energy. Energy 36(11):6567-6576. doi:10.1016/j.energy.2011.09.006.

45. HEP (Hrvatska elektroprivreda) - Operator distribucijskog sustava d.o.o.(2010) http://www.hep.hr/ods/kupci/kucanstvo.aspx. Accessed 23 Apr 2015.

46. Lund H, Kempton W (2008) Integration of renewable energy into the transport and electricity sectors through V2G. Energy Policy 36:3578-3587.

47. Kempton W, Tomic J, Letendre S, Brooks A, Lipman T (2001) Vehicle-to-grid power: battery, hybrid, and fuel cell vehicles as resources for distributed electric power in California. UCD-ITS-RR-01-03, 2001.

48. Kiviluoma J, Meibom P (2011) Methodology for modelling plug-in electric vehicles in the power system and cost estimates for a system with either smart or dumb electric vehicles. Energy 36:1758-1767.

49. Madzharov D, Delarue E, D'haeseleer W (2014) Integrating electric vehicles as flexible load in unit commitment modelling. Energy 65:285-294.

50. Honarmand M, Zakariazadeh A, Jadid S (2014) Optimal scheduling of electric vehicles in an intelligent parking lot considering vehicle-to-grid concept and battery condition. Energy 65:572-579.

51. Šare A, Krajačić G, Pukšec T, Duić N (2013) The impact of electrification in the transport sector on the power curve, and the integration of renewable energy sources in to the power systems of the Dubrovnik region. 8th SDEWES Conference, Dubrovnik, Croatia, 2013.

52. European Commission (2015) Quarterly report on European electricity markets. Market Observatory for Energy. Energy, Volume 8, issue 1.

\section{Submit your manuscript to a SpringerOpen ${ }^{\circ}$ journal and benefit from:}

- Convenient online submission

- Rigorous peer review

- Immediate publication on acceptance

- Open access: articles freely available online

- High visibility within the field

- Retaining the copyright to your article

Submit your next manuscript at $>$ springeropen.com 